\title{
Misconceptions and computational errors in algebra: an analysis
}

\author{
Gloria Mac P. Espelita \\ paragasgloriamac@gmail.com \\ Laguna State Polytechnic University, Sta. Cruz, Laguna 4009 Philippines
}

\begin{abstract}
This study was conducted to determine the errors of students when working with functions and relations. Specifically, the common conceptual and computational errors in relations and functions in Algebra were identified. The researcher prepared an activity that was assessed based on accuracy of material, clarity of material, appeal to target users and presentation and originality. The significant difference between the pre-test and post-test errors' scores of the students in terms of conceptual skills and computational skills and the significant difference between the pre-test and post test score of the students were also determined.

The study employed a quantitative research design. It made use of quantitative approach in gathering the required data. A total of thirty nine (39) respondents of Grade 8 students of Paaralang Sekundarya ng Lucban Integrated School, Lucban, Quezon were involved. They were chosen through convenience sampling. The instruments used in the study were pretest and posttest to determine the significant difference between the errors; questionnaires were administered to determine the level of acceptability of the teacher-made module.

The data gathered were analyzed and interpreted with the use of t-test dependent samples and weighted mean. It was found that there is a significant difference on the conceptual errors and computational errors committed by the students in the pre-test and the post-test. The p-value of 12.202 was compared to the critical value of 2.201 at the .05 level of significance is significant and the computed p-value of 14.320 was compared to the critical value of 2.110 at 0.05 level of significance is significant on the conceptual and computational errors respectively.

The level of acceptability of the teacher-made module with the overall means of 3.43, 3.49, 3.47 and 3.41 indicates that the module was highly acceptable in terms of accuracy of the material, clarity of the material, appeal to the target users and presentation and originality respectively.

The level of student's performance in pretest and posttest showed fair performance in the pre-test $(\mathrm{M}=11.9, \mathrm{SD}=3.57)$ and excellent performance in the post-test $(\mathrm{M}=24.23, \mathrm{SD}=2.06)$. The computed standard deviation indicates that the students' scores in the post-test were less dispersed compared with their pre-test scores.

The computed p-value of -25.249 was compared to the tabular value of 2.024 at 0.05 level of significance is significant. This means that there is a significant difference between the mean scores of the students in pretest and posttest.

It was concluded that the there is a significant difference between the error scores of the students given in conceptual and computational skills before and after using the remediation activities.

In view of the findings and conclusion of the study, the following recommendation is given: Future researchers may use other topic that students usually committing errors; Teachers may also create and developed more remediation activities and other forms of remedy to deal with errors of the said topic; An acceptability test of the research output can be tested by more Mathematics teachers and that a revision of the material can be made for its development and validation; An improvement of the remediation activity that characterized by clear format and letter forms; Teachers may improve learning motivation and strategy in teaching mathematics to improve performance and achievement of the students.
\end{abstract}

Keywords: Misconceptions; Computational Errors; Errors; Activities; Remediation Activities

\section{Introduction}

Errors play a pivotal role in the understanding of the concepts particularly in Mathematics. It is naturally a part of the teaching and learning process, that is why most students are committing mistakes when solving problems. According to NCTM (2000) in Foster (2019), "Problem solving means engaging in a task for which the solution method is not known in advance. In order to find a solution, students must draw on their knowledge, and through this process, they will often develop new mathematical understandings. Thus, problem solving is more than a method for it is dependent on how one understands the problem.

Herholdt and Sapire (2014) stated that error analysis, also referred to error pattern analysis, it is the study of errors in learners' work with a view to finding explanations for these reasoning errors. Not all errors can be attributed to reasoning faults; some are simply careless errors, identified as "slips" which can easily be corrected if the faulty process is pointed out 
to the learner. It is concerned with the pervasive errors which learners make, based on their lack of conceptual or procedural understanding (Geller \& Yovanoff , 2009)

With these, teachers provide students with activities that will develop deeper understanding about a certain field. Activities can also uplift the learning attributes such as knowledge, skills and potential of learners. In addition, activities make the students engage, involve and make an investment of time and energy in learning (Anilao, 2012).

\subsection{Conceptual framework}

The concept of determining the errors in Algebra is extremely significant in all aspects of society today in the field of Mathematics teaching. The researcher considered it necessary to conduct a study on the said area to help the teachers and students to be mindful of the possible errors and misconceptions involving relations and functions so as to put remedy to the problems. Therefore, remediation activities should be developed to determine the common errors of the students in the filed so as remedy students' errors involving relations and functions. This strategy of using errors would likely suit in improving the understanding of students in relations and functions. In other words, it is expected this study may contribute in making the performance of students better in dealing with relations and functions as well as increasing the awareness of teachers on the possible errors in the teaching process for proper avoidance.

\begin{tabular}{|c|c|c|}
\hline Input & Process & Output \\
\hline Results of the pretest & $\begin{array}{c}\text { Administration of } \\
\text { Remediation Activities }\end{array}$ & $\begin{array}{c}\text { Acceptable Remediation } \\
\text { Activities }\end{array}$ \\
\hline $\begin{array}{c}\text { Identification of errors of } \\
\text { students }\end{array}$ & $\begin{array}{l}\text { Administration of Post } \\
\text { test }\end{array}$ & $\begin{array}{l}\text { Enhanced students' } \\
\text { performance }\end{array}$ \\
\hline
\end{tabular}

Fig. 1. Modified Input-Process-Output (IPO) Model of Remediation Activities as Basis for Relations and Functions Errors

\subsection{Statement of the problem}

The study attempts to develop remediation activities as instrument in dealing with errors and misconception in relations and functions of selected students in Paaralang Sekundarya ng Lucban Integrated School, Lucban Quezon:

Specifically, it sought to achieve the following objectives:

1. What are the common conceptual and computational errors in relations and functions in Algebra ?

2. What is the level of acceptability of the activity as remedy to specific errors in terms of:

2.1 accuracy of material

2.2 clarity of material

2.3 appeal to target users

2.4 presentation and originality

3. Is there are significant difference between the pre-test and post-test errors' scores of the students in:

3.1 conceptual skills;

3.2 computational skills

4. Is there a significant difference between the pre-test and post test score of the students?

\section{Methodology}

\subsection{Research design}

The study made use of the quantitative approach of research in gathering the required data. Bhandari (2021) defines quantitative research as the process of collecting and analyzing numerical data. It can be used to find patterns and averages, make predictions, test causal relationships, and generalize results to wider populations. It is said to be quantitative research since, pre-test and post-test was administered in order to identify the errors of the students and determine the effectiveness of the remediation activities in dealing with the students' errors in the said field.

\subsection{Participants of the study}

The respondents were chosen using convenience sampling. According to Gaile (2020), data gathering with convenience 
sampling comes from people that are the easiest to reach or contact. It is sampling method beyond the willingness and availability of people to participate in the work. It does not require a random sample since the only criteria to meet is an agreement to become part of the study. The study was conducted in Paaralang Sekundarya ng Lucban Integrated School at Lucban, Quezon which is the researcher's teaching. Since, the study focused on determining the specific errors of students particularly working relations and functions, the respondents of the study were the 39 Grade 8 students for the school year 2020-2021. This is because the area is usually the introductory part to their Algebra subject and that they are the ones who can give the most appropriate data or information.

\subsection{Instrumentation}

The researcher utilized a self-made pretest and posttest to gather information about the students' errors particularly on relations and functions.

A questionnaire was used as the main data gathering instrument for this study. The questionnaire was adapted from the study of Pabilonia (2014) regarding the level of acceptability of the developed remediation activities made by the researcher and was submitted to her research adviser for comments and suggestions on the layout and proper statement constructions. Comments were considered for the revision of the instrument. After these, the initial draft of the questionnaire was tried out to ten (10) Grade 9 Mathematics teacher in Paaralang Sekundarya ng Lucban Integrated School. The favorable findings verify that the questionnaire is valid.

\subsection{Data gathering procedure}

The study was concerned with identifying the errors of students when working with relations and functions as well as the development of remediation activities in dealing with the students' errors in the said field. A letter of endorsement was sought from the Assistant Schools Division Superintendent Principal of Division of Quezon then a letter of approval from the Principal of Paaralang Sekundarya ng Lucban Integrated School to allow the researcher to conduct the study. After this, the conduct of the test and survey with respondents were scheduled. Test was given to the respondents to determine the common errors of the students when working with relations and functions which become the basis in developing remediation activities. The effectiveness of the tool was measured.

For more reliable an valid results, the following steps were done by the researcher:

A thirty-item multiple choice type of assessment test was constructed. The content of the assessment was based on the second quarter competencies provided in the $\mathrm{K}$ to 12 curriculum guide based from the table of specification. Clear and accurate directions were given to avoid confusion on the part of the respondents. Each question has four (4) choices to lessen the instance of guessing. The research adviser and selected Mathematics teachers from Paaralang Sekundarya ng Lucban Integrated School were asked to check the content of the test in terms of the distribution of questions, grammar and accuracy of content of the test before administration. The test was administered to the thirty-nine (39) Grade -8 students in Paaralang Sekundarya ng Lucban Integrated School after validation. After administering it to the students, the researcher checked the questionnaires to identify their common errors. Then conducted an interview to some students. Questions were asked based from their answers in order for the researcher to identify the errors of the students regarding the topics in relations and functions. This helped in the collection of data to determine whether there is a really an improvement in the learners' achievement.

After knowing the result of the test, the researcher determined the errors that the students committed which became the basis of the remediation activities. Likewise, the researcher conducted an advance research about relations and function to prepare the remediation activities beforehand. It was then checked by selected teachers and her adviser before distribution. Face validation was done for the remediation activities before it was distributed. Through the comments and suggestions of evaluators of teachers in Mathematics, English and Educational Technology the remediation activities were improved. After the validation, the remediation activities were distributed to the students of Paaralang Sekundarya ng Lucban Integrated School. After the distribution and presentation of the remediation activities, the post test was given to find out how effective the instructional material was.

The researcher adapted a questionnaire from the study of Pabilonia (2014) regarding the level of acceptability of the developed remediation activities. Adapted questionnaire for acceptability was given to 15 teachers with specialization aligned to this study.

\subsection{Data analysis}

The data collected were tallied, tabulated, analysed, and interpreted. To compare the pre-test and post-test scores of the learners and to see whether there is a significant difference between the error scores, t-Test dependent samples was used. To determine the level of acceptability of remediation activities, the formula for the weighted mean was used. 


\section{Results and discussion}

Table 1. Common conceptual errors committed by students

\begin{tabular}{|c|c|c|c|c|c|}
\hline \multirow{2}{*}{ Topics } & \multirow{2}{*}{$\begin{array}{c}\text { Item } \\
\text { placement }\end{array}$} & \multicolumn{2}{|c|}{ Pre-test } & \multicolumn{2}{|c|}{ Post-test } \\
\hline & & $f$ & $\%$ & $f$ & $\%$ \\
\hline \multirow{4}{*}{ Illustrate a relation and a function } & 1 & 20 & 51.3 & 3 & 7.7 \\
\hline & 2 & 25 & 64.1 & 2 & 5.1 \\
\hline & 3 & 14 & 35.9 & 3 & 7.7 \\
\hline & 5 & 29 & 74.4 & 9 & 23.1 \\
\hline Average & & 22 & 56.4 & 4.25 & 10.9 \\
\hline \multirow{2}{*}{ Verifies if a given relation is a function } & 6 & 31 & 79.5 & 10 & 25.6 \\
\hline & 14 & 21 & 53.8 & 8 & 20.5 \\
\hline Average & & 26 & 66.7 & 9 & 23.1 \\
\hline $\begin{array}{l}\text { Determines the dependent and independent } \\
\text { variables }\end{array}$ & 9 & 26 & 66.7 & 8 & 20.5 \\
\hline Average & & 26 & 66.7 & 8 & 20.5 \\
\hline \multirow{3}{*}{ Finds the domain and the range of a function } & 4 & 10 & 25.6 & 0 & 0.00 \\
\hline & 7 & 13 & 33.3 & 2 & 5.1 \\
\hline & 22 & 23 & 59.0 & 8 & 20.5 \\
\hline Average & & 15.3 & 29.5 & 3.33 & 8.5 \\
\hline $\begin{array}{l}\text { Graphs a linear function's (a) domain; (b) range; } \\
\text { (c) table of values; (d) intercepts; slope }\end{array}$ & 16 & 29 & 74.4 & 6 & 15.4 \\
\hline Average & & 29 & 74.4 & 6 & 15.4 \\
\hline Solve problems involving linear functions & 25 & 23 & 59.0 & 8 & 20.5 \\
\hline Average & & 23 & 59.0 & 8 & 20.5 \\
\hline
\end{tabular}

Table 1 shows one of the common errors committed by the students is on how to illustrate a function and a relation. There were four items under this topic which the students find challenging. On the average, $56.4 \%$ percent of the students committed errors on 1, 2, 3, and 5. In item number 1, the students mostly answered graph instead of mapping about the representation of a function that uses pictures and arrows; in item number 2, they answer horizontal line test instead of the vertical line test in representing a function where the line intersect the line at exactly one point; while in item number 3 , some of the students errors is answering domain in the set from which the y-values are taken is the co-domain or the actual set of all second elements of the ordered pairs instead of range; in item number 5, the process of substituting the entire function into other function most students answered linear function instead of functional notation. In the post-test, it is interesting to note that the errors committed by the students in this topic lowered to $10.9 \%$. In this competency, more than half of the students committed errors in the pre-test which was toned down by an approximate of $46 \%$ in the post-test.

Another topic which the students find difficult is on verifying if a given relation is a function. On the average, the $66.7 \%$ committed errors in item number 6 and 14. In item number 6 , students answers varies in one-to-one correspondence, manyto-one correspondence and one-to-many correspondence in the question which is the type of relation is described by the set of ordered pars $\{(1,5),(2,2),(2,2),(1,1)\}$ instead of many-to-many correspondence; in item number 14 , given the four sets of ordered pairs, which of this set of ordered pairs define a function. The average of errors committed by the students is dropped to $23.1 \%$ in the post test. It is approximately $33 \%$ was lessened in the students errors.

While, the topic of determining the dependent and independent variables, from $66.7 \%$ errors by the students in the pretest specifically they are struggling in determining which is the dependent variable and independent variable, down to 20.5 $\%$ in the post test in the item number 9 . In this competency, more than two thirds of the students committed errors in the pre-test which was decreased by an approximate $46 \%$ in the post test.

In the item number 4, 7 and 22 under the topic of domain and range, it has an average of $29.5 \%$ committed errors of the students in pre-test. In the post test, the errors committed by the students are reduced to $8.5 \%$.In item number 4 , what should not be the equivalent of the denominator in finding the domain and range of a relation involving a fraction, most of the students answered 1 instead of 0 ; in item number 7 with the question, what would be the domain, given the set of ordered pairs $\{(1,5),(4,2),(2,9),(7,2)\}$, the student answer varies but the correct answer is $\{1,4,2,7\}$; while the question in the item number 22 about the possible rage of the function $f(x)=x+1$, the students mostly answer the set of real numbers less than 1 or set of real numbers greater than 1 instead the correct answer all set of real numbers. .In this topic, it is approximately $21 \%$ is lessened in the committed errors of the students.

In the topic graphing of linear functions, the average committed errors of the students in the pre-test is $74.4 \%$ dropped to $15.4 \%$ in the post test in item number 16. In this item, the students feel stressed in finding the range of the given equation. 
It is approximately $60 \%$ of errors is decreased from the pre-test average to the post test average; more than four-fifths of the students committed errors is toned down.

In the last topic of relation and functions which is solving problem involving linear functions, the average committed errors of the students in the pre-test is $59 \%$ while $20.5 \%$ in the post test in item number 25 . In this item, given the statements, (I) radicand must be non-negative; (II) radical must be greater than or equal to zero; (III) radical must less than or equal to zero, which is true in finding the domain and range of a relation involving a radical with an even index, the students mostly answer I and III instead I and II. It is almost two-thirds of the students errors in this topic is lowered by an approximate of $39 \%$ in the post test.

According to Große and Renkl (2007) in Rushton (2018), emphasized that introducing errors in the learning process encourages students to reflect on what they know and then be able to create clearer and more complete explanations of the solutions. The presentation of "incorrect knowledge can induce cognitive conflicts which prompt the learner to build up a coherent knowledge structure". Presenting a cognitive conflict through erroneously worked exercises triggers learning episodes through reflection and explanations, which leads to deeper understanding.

Table 2. Common computational errors committed by students

\begin{tabular}{|c|c|c|c|c|c|}
\hline \multirow{2}{*}{ Topics } & \multirow{2}{*}{ Item placement } & \multicolumn{2}{|c|}{ Pre-test } & \multicolumn{2}{|c|}{ Post-test } \\
\hline & & $\mathbf{F}$ & $\%$ & $\mathbf{F}$ & $\%$ \\
\hline \multirow{2}{*}{ Illustrate a relation and a function } & 12 & 25 & 64.1 & 12 & 30.8 \\
\hline & 13 & 14 & 35.9 & 1 & 2.6 \\
\hline Average & & 19.5 & 50.0 & 6.5 & 16.7 \\
\hline Verifies if a given relation is a function & 15 & 21 & 53.8 & 3 & 7.7 \\
\hline Average & & 21 & 53.8 & 3 & 7.7 \\
\hline \multirow{2}{*}{$\begin{array}{c}\text { Determines the dependent and independent } \\
\text { variables }\end{array}$} & 10 & 19 & 48.7 & 6 & 15.4 \\
\hline & 11 & 23 & 59.0 & 4 & 10.3 \\
\hline Average & & 21 & 53.8 & 5 & 12.8 \\
\hline \multirow{3}{*}{ Finds the domain and the range of a function } & 8 & 30 & 76.9 & 14 & 35.9 \\
\hline & 23 & 30 & 76.9 & 13 & 33.3 \\
\hline & 24 & 33 & 84.6 & 14 & 35.9 \\
\hline Average & & 31.5 & 80.8 & 13.5 & 34.6 \\
\hline \multirow{5}{*}{$\begin{array}{l}\text { Graphs a linear function's (a) domain; (b) range; } \\
\text { (c) table of values; (d) intercepts; slope }\end{array}$} & 17 & 18 & 46.2 & 1 & 2.6 \\
\hline & 18 & 20 & 51.3 & 4 & 10.3 \\
\hline & 19 & 31 & 79.5 & 23 & 59.0 \\
\hline & 20 & 21 & 53.8 & 3 & 7.7 \\
\hline & 21 & 32 & 82.1 & 15 & 38.5 \\
\hline Average & & 24.4 & 62.6 & 9.2 & 23.6 \\
\hline \multirow{5}{*}{ Solve problems involving linear functions } & 26 & 15 & 38.5 & 12 & 30.8 \\
\hline & 27 & 31 & 79.5 & 11 & 28.2 \\
\hline & 28 & 22 & 56.4 & 4 & 10.3 \\
\hline & 29 & 29 & 74.4 & 10 & 25.6 \\
\hline & 30 & 30 & 76.9 & 6 & 15.4 \\
\hline Average & & 25.4 & 65.1 & 8.6 & 22.1 \\
\hline
\end{tabular}

Table 2 presents the number of committed errors in pretest and posttest particularly in computational errors. There were two items under the topic of illustrating relation and a function. On the average, $50 \%$ percent of the students committed errors on 12 and 13; it lowered to $16.7 \%$ in the posttest. Given four arrow diagrams in item number 12 and given four graphs in item number 13, which of the following relation is not a function; the students are having a difficulty on analyzing which is a function using arrow diagram and graphs. In this topic, two-thirds of the students committed errors in the pre-test which was decreased by an approximate of $33.3 \%$ in the post-test.

The second topic which the students find challenging is on verifying if a given relation is a function. On the average, the $53.8 \%$ committed errors in item number 15 . Given four equations, which of the following is not a function; the students are having struggle on finding which the function, given an equation is. The average of errors committed by the students is plunged to $7.7 \%$ in the post test. It is approximately $46.1 \%$ was diminished in the students errors.

Whereas, the topic of determining the dependent and independent variables, from $53.8 \%$ errors by the students in the pre-test specifically analyzing the given statement which is the dependent and independent variable, dropped to $12.8 \%$ in the post test in the item number 10 and 11. In this competency, approximately $40 \%$ was decreased from the pretest to posttest. 
In the topic finding the domain and range of a function, the average committed errors of the students in the pre-test is $80.8 \%$ dropped to $34.6 \%$ in the post test in item number 8,23 and 24 . In item number8, find the range of the given equation $\mathrm{x} 2+\mathrm{y}-3=0$; the common errors of the students is the used of the mathematical symbol. In item number 23 , given the fractional form function, which cannot be a possible domain, the common errors of the students is they do not have enough knowledge on the limits of the denominator of fractions same with item number 24, which cannot be an element of the domain of the function given a square root. It is approximately $46.2 \%$ of errors is decreased from the pre-test average to the post test average; almost half of the students committed errors is lessened.

In the item number $17,18,19,20$ and 21 under the topic graphing of linear functions, it has an average of $62.6 \%$ committed errors of the students in pre-test. In the post test, the errors committed by the students are reduced to $23.6 \%$. in items number 17 and 18 deals with find the slope, the y-intercept given an equation while in item number 19, 20 and 21 , deals in finding the equation of a line given a two points and point and slope. In this topic, it is approximately $39.0 \%$ is reduced in the committed errors of the students.

In the last topic of relation and functions which is solving problem involving linear functions, the average committed errors of the students in the pre-test is $65.1 \%$ while $22.1 \%$ in the post test in item number $26,27,28,29$ and 30 . In this items, it deals with solving problem which is based on real life situations. Some of the students got the write computation but cannot interpret it while some of the students commit errors in computing the value. It is almost two-thirds of the students errors in this topic is lowered by an approximate of $43 \%$ in the post test. It is approximately $43 \%$ of errors is lowered from the pre-test average to the post test average; more than two-thirds of the students committed errors is lessened.

The gathered result support the statement of Hansen et al. (2011), stated that mathematical errors provide a useful insight to a more radical shift in teachers' thinking and understanding, suggesting that far from trigging to teach to avoid children from misconceptions. Therefore in order to so, students have to be engaged with mathematical question sets, discuss the errors with peers and explore why this errors have been made. Through an effective mechanism for assessment learning and with sensitive handling can enable children to learn from their mathematical mistakes.

Table 3. Level of acceptability in terms of accuracy of the material

\begin{tabular}{|c|c|c|c|}
\hline Statements & Mean & S.D. & Verbal Interpretation \\
\hline $\begin{array}{l}\text { The activity has clear instructions for each type of } \\
\text { activities that are in the sequence for understanding. }\end{array}$ & 3.53 & 0.516 & Highly acceptable \\
\hline $\begin{array}{l}\text { The activity presents questions arranged in increasing } \\
\text { level of difficulty }\end{array}$ & 3.27 & 1.163 & Acceptable \\
\hline $\begin{array}{l}\text { The activity contains enough exercises that measure } \\
\text { the mastery of the lesson. }\end{array}$ & 3.40 & 0.632 & Highly acceptable \\
\hline The activity components arranged logically. & 3.53 & 0.516 & Highly acceptable \\
\hline Overall Mean & 3.43 & & Highly Acceptable \\
\hline \multicolumn{4}{|l|}{ Legend: } \\
\hline Highly Acceptable (HA) & & & \\
\hline Acceptable (A) & & & \\
\hline 2.20-2.79 Moderately Acceptable (MA) & & & \\
\hline Somewhat Acceptable (SA) & & & \\
\hline 1.00-1.59 Not Acceptable (NA) & & & \\
\hline
\end{tabular}

The acceptability of the teacher-made module was evaluated in terms of accuracy. The students perceived that the activity components were highly acceptable $(M=3.53, S D=0.516)$ because clear instructions were given that increased students' understanding $(M=3.53, S D=0.516)$. The module provides activities that promote mastery of the lesson $(M=3.40$, $S D=0.632)$ because the questions were arranged in increasing level of difficulty $(M=3.27, S D=1.163)$.

The overall mean of 3.43 indicates that the module was highly acceptable in terms of accuracy. The module provides properly sequenced activities that promotes master. It supports the statement of De la Peña (2006) cited in Salvaleon (2011) stating that learning materials affect the learners performance and should be based on the activities prescribed by the lesson plans in order to meet the objective of the lesson.

Table 4. Level of acceptability in terms of clarity of the material

\begin{tabular}{lccc}
\hline \multicolumn{1}{c}{ Statements } & Mean & S.D. & Verbal Interpretation \\
\hline $\begin{array}{l}\text { The activity contains statements for each type of } \\
\text { assessment that are in sequence for understanding. }\end{array}$ & 3.53 & 0.743 & Highly acceptable \\
$\begin{array}{l}\text { The activities are organized and characterized by clear } \\
3.33\end{array}$ & 0.724 & Acceptable
\end{tabular}


The activity contains directions that are easy to $3.60 \quad 0.507 \quad$ Highly acceptable comprehend.

\begin{tabular}{lll}
\hline \multicolumn{1}{c}{ Overall Mean } & $\mathbf{3 . 4 9}$ & Highly Acceptable \\
\hline $3.40-3.99$ & Highly Acceptable $(H A)$ & \\
$2.80-3.39$ & Acceptable (A) & \\
$2.20-2.79$ & Moderately Acceptable (MA) & \\
$1.60-2.19$ & Somewhat Acceptable (SA) & \\
$1.00-1.59$ & Not Acceptable (NA) &
\end{tabular}

The acceptability of the teacher-made module was evaluated in terms of clarity. The respondents agreed that the activity contains statements for each lesson that are in sequence for understanding were highly acceptable $(M=3.53, S D=0.743)$. The activity was also organized by a clear format and letter forms $(M=3.33, S D=0.724)$ and includes directions that are easy to comprehend $(M=3.60, S D=0.507)$.

The overall mean of 3.49 indicates that the module was highly acceptable in terms of clarity. This only indicates that the content of the module is clear and understandable. As what Echevarria \& Graves (2003) in Jarrar (2014) teachers should take the following considerations while teaching students with learning difficulties which are locating objectives written for students to see along with selected vocabulary provides the kind of structure with those students need.

Table 5. Level of acceptability in terms of appeal to the target user

\begin{tabular}{|c|c|c|c|}
\hline Statements & Mean & S.D. & Verbal Interpretation \\
\hline $\begin{array}{l}\text { The activities are visually enticing and adequately } \\
\text { motivating. }\end{array}$ & 3.40 & 0.737 & Highly acceptable \\
\hline $\begin{array}{l}\text { Captured students' interest to learn the lesson from the } \\
\text { instructional materials. }\end{array}$ & 3.47 & 0.640 & Highly acceptable \\
\hline $\begin{array}{l}\text { Could develop the learner's confidence in learning } \\
\text { materials through the exercises presented therein. }\end{array}$ & 3.47 & 0.516 & Highly acceptable \\
\hline $\begin{array}{l}\text { Stimulate the learners to develop interest in } \\
\text { Mathematics. }\end{array}$ & 3.53 & 0.640 & Highly acceptable \\
\hline Allow the students to proceed at their own rate. & 3.47 & 0.640 & Highly acceptable \\
\hline Overall Mean & 3.47 & & Highly Acceptable \\
\hline $\begin{array}{ll}\text { Legend: } & \\
3.40-3.99 & \text { Highly Acceptable }(H A) \\
2.80-3.39 & \text { Acceptable }(A) \\
2.20-2.79 & \text { Moderately Acceptable }(M A) \\
1.60-2.19 & \text { Somewhat Acceptable }(S A) \\
1.00-1.59 & \text { Not Acceptable }(N A)\end{array}$ & & & \\
\hline
\end{tabular}

The acceptability of the teacher-made module was evaluated in terms of appeal to the target users. The respondents observed that the activities are visually-enticing and adequately motivating were highly acceptable $(M=3.40, S D=0.737)$ because it captured the students' interest to learn the lesson from the instructional material $(M=3.47, S D=0.640)$ and develop the learner's confidence in learning Mathematics $(M=3.47, S D=0.516)$. The module provides activities that develop interest in mathematics $(M=3.47, S D=0.640)$ as well as allows them to proceed at their own rate $(M=3.53, S D=0.640)$.

The overall mean of 3.47 indicates that the module was highly acceptable in terms of appeal to the target users. The module provides appeal and motivation to the target users. It supports the statement of De la De la Cruz (2010) who stated that some learners are visually attuned to looking at things in picture. These are many opportunities in which students could create an illustration or a drawing to explain their thinking or to show how they understand the concept.

Table 6. Level of acceptability in terms of presentation and originality

\begin{tabular}{lccc}
\hline \multicolumn{1}{c}{ Statements } & Mean & S.D. & Verbal Interpretation \\
\hline $\begin{array}{l}\text { Could have improved learning motivation through } \\
\text { visual appeal and learner interaction. }\end{array}$ & 3.33 & 0.724 & Acceptable \\
$\begin{array}{l}\text { Design and appearance of the activity are exceptionally } \\
\text { different from other activities created. }\end{array}$ & 3.33 & 0.617 & Acceptable \\
$\begin{array}{l}\text { Consists of exercises and activities originally devised } \\
\text { for a particular topic. }\end{array}$ & 3.47 & 0.640 & Highly acceptable \\
$\begin{array}{l}\text { The activity was presented with proper diction evident } \\
\text { M }\end{array}$ & 3.33 & 0.724 & Acceptable
\end{tabular}


in the instruction given for each task.

The activities were presented in a way suitable to the $\quad 3.60 \quad 0.507 \quad$ Highly acceptable students' level of capability.

\begin{tabular}{lll}
\hline \multicolumn{1}{c}{ Overall Mean } & $\mathbf{3 . 4 1}$ & Highly Acceptable \\
\hline Legend: & & \\
$3.40-3.99$ & Highly Acceptable $(H A)$ & \\
$2.80-3.39$ & Acceptable (A) & \\
$2.20-2.79$ & Moderately Acceptable (MA) & \\
$1.60-2.19$ & Somewhat Acceptable (SA) & \\
$1.00-1.59$ & Not Acceptable (NA)
\end{tabular}

The acceptability of the teacher-made module was evaluated in terms of presentation and originality. The respondents observed that the module improved learning motivation though visual appeal and learner interaction were acceptable $(M=3.33, S D=0.724)$ because the design and appearance of the activity were exceptionally different form other activities $(M=3.33, S D=0.617)$ and the proper diction in every task was evident $(M=3.33, S D=0.724)$. The module provides exercises and activities originally devised for a particular topic were highly acceptable $(M=3.47, S D=0.640)$ were presented in a way suitable to the students' level of capability $(M=3.60, S D=0.507)$.

The overall mean of 3.41 indicates that the module was highly acceptable in terms of presentation and originality. The module provides activities and exercises that were suitable to the students' ability. The data serve as a vivid information to the words of Bell and Growner (2000) in Flores (2012), who had once made an emphasis in material development. They firmly believed that a learning material should at all cost engaging to target users to come up with the best learning possible.

Table 7. Difference on the conceptual and computational errors committed by students

\begin{tabular}{|c|c|c|c|c|c|c|}
\hline \multirow[t]{2}{*}{ Errors } & \multicolumn{2}{|c|}{ Mean } & \multirow{2}{*}{$\begin{array}{c}\text { Mean } \\
\text { Difference }\end{array}$} & \multirow{2}{*}{$\begin{array}{c}\text { t- } \\
\text { value }\end{array}$} & \multirow{2}{*}{$\begin{array}{c}\text { Critical } \\
\text { value }\end{array}$} & \multirow[t]{2}{*}{ Analysis } \\
\hline & Pre & Post & & & & \\
\hline Conceptual & $\begin{array}{c}22.0 \\
(s d=6.45)\end{array}$ & $\begin{array}{c}5.6 \\
(s d=3.23)\end{array}$ & 16.4 & $12.202 *$ & 2.201 & Significant \\
\hline Computational & $\begin{array}{c}24.7 \\
(s d=6.010)\end{array}$ & $\begin{array}{c}8.7 \\
(s d=5.831)\end{array}$ & 16.0 & $14.320 *$ & 2.110 & Significant \\
\hline
\end{tabular}

*p $\leq$ 05,sig,2-tailed

It can be gleaned from Table 7 that the average conceptual errors committed by the students in the pre-test was 22.0 and 5.6 in the post-test. The computed standard deviation indicates a less spread of scores in the post-test than in the pre-test. It was found that there is a significant difference on the conceptual errors committed by the students in the pre-test and the post-test. The p-value of 12.202 is significant at the .05 level of significance.

This means that the difference in the data comparing the errors in pre-test and post test results indicates the applicability of the teacher-made module as remedy to errors in the functions and relations. The wide gap between the data in the pretest and posttest is also evident. As what Lucariello (2013) stated, errors can become rigid and resistant to revision later on. Teachers serve as one of the main factor in that matter. It is important for teachers to know about the preconceptions of their students because learning depends on and is related to student prior knowledge.

From the table, the average computational errors committed by the students in the pre-test were 24.7 and 8.7 in the posttest. Likewise, the table shows that both tests obtained computed standard deviation of 6.010 and 5.831 . The computed pvalue of 14.320 is compared to the critical value of 2.110 at 0.05 level of significance. Therefore, there is a significant difference between the pretest and posttest scores of the students under the computational error. Hence, the use of teachermade module as a remedy for errors in functions and relations is operative.

According to Pound and Lee (2011), that teaching in creative ways suitable to the students will provide stimulating classroom environment which will be a source of experience and learning. These would promote creativity on the part of the learners which could develop their deeper understanding towards the subject.

Table 8. Level of students' performance in the pre-test and post test scores

\begin{tabular}{cccccc}
\hline & Lowest score & Highest score & Mean & Standard deviation & Analysis \\
\hline Pre-test & 5 & 18 & 11.90 & 3.57 & Fair \\
Post-test & 21 & 28 & 24.23 & 2.06 & Excellent \\
\hline
\end{tabular}




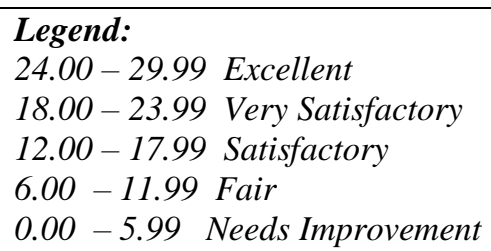

The students showed fair performance in the pre-test $(M=11.9, S D=3.57)$ and excellent performance in the post-test $(M=24.23, S D=2.06)$. The computed standard deviation indicates that the students' scores in the post-test were less dispersed compared with their pre-test scores.

This means that the difference in the data comparing the highest scores and lowest scores in pre-test and post test results shows the relevant of the teacher-made module as remedy to errors in the functions and relations. The wide gap between the comparison of the data in the pretest and posttest is also manifest. As what Jarrar (2014) recommended that teachers should give more emphasis to remedial education techniques while teaching, and cooperate with remedial teachers to help low achievers and make progress in the achievement.

Table 9. Difference between the pre-test and post test scores

\begin{tabular}{cccccc}
\hline \multicolumn{2}{c}{ Mean } & $\begin{array}{c}\text { Mean } \\
\text { difference }\end{array}$ & t-value & Critical value & Analysis \\
\cline { 1 - 2 } Pre-test & Post-test & & -25.649 & 2.024 & Significant \\
\hline 11.90 & 24.23 & 12.33 & & &
\end{tabular}

From the table, it can be seen that the means in the pretest and posttest for the 30-item test were 11.90 and 24.23 , with a mean difference of 12.33 . The computed p-value of -25.249 is compared to the tabular value of 2.024 at 0.05 level of significance. Since the p-value is greater than the tabular value, therefore the null hypothesis is rejected. Thus, there is a significant difference between the pretest and posttest scores of the students after using the teacher-made module. De la Pena (2006) cited in Salvaleon (2011) stated that the use of learning materials affect the learners performance and should be based on the activities prescribed by the lesson plans in order to meet the objective of the lesson.

This means that there is a significant difference in the data comparing the mean scores in pre-test and post test results specifies the wide range between the mean scores. It shows that the used of teacher-made module is very substantial to remedy errors in relations and functions.

\section{Conclusion}

Based on the findings of the study, the researcher came up with the conclusion:

The Grade 8 learners committed conceptual and computational errors. The highly acceptable activities served as remedy to this, as a notable increase in the students' scores was observed.

\section{Recommendations}

In this view of the presented conclusions of this research, the following are hereby recommended:

- Teachers may use other teaching strategy in teaching mathematics to improve performance and achievement of the students.

- Teachers may also construct more remediation activities and other forms of remedy to deal with errors of the said topics.

- $\quad$ Teachers may improve learning motivation through visual appeal and learner interaction and design an exceptionally different activities from other activities created.

- An acceptability test of the research output can be tested by more Mathematics teachers and that a revision of the material can be made for further development.

- An improvement of the remediation activity that presents questions arranged in increasing level of difficulty, an organized and characterized by clear format and letter forms may be made to gain and a more favorable response from students.

- Future researchers may use other topic that students usually committing errors.

- Further improvement of this research is also recommended. 


\section{References}

Anilao, Alyssa, V. (2012). Development and Acceptability of Integrative Activities in Selected tooisninTrigonometry. Undergraduate Thesis, Lucban, Quezon: Southern Luzon State University.

Bhandari, P. (2020). An Introduction to Quantitative Research. Retrieved from https://www.scribbr.com/methodology/quantitative-research/

De la Cruz, Teresita V. (2010). Rudiments and Know-How of Facilitating Learning. Lucban, Quezon: Southern Luzon StateUniversity College of Teacher Education.

Flores, Raffy (2012). Activities oriented Approach on the Application of Right Triangle in Trigonometry. Undergraduate Thesis. Lucban,Quezon: Southern Luzon State University.

Foster, C. (2019). The Fundamental Problem with Teaching Problem Solving. Association of Teachers of Mathematics. https://www.atm.org.uk/write/MediaUploads/Journals/MT265/MT26503.pdf

Gaille, L. (2020). 15 Advantages and Disadvantages of Convenience Sampling. Retrieved from https://vittana.org/15-advantages-and-disadvantages-ofconvenience-sampling

Geller \& Yovanoff, (2009). "Diagnostic Assessments in Mathematics to Support Instructional Decision Making," Practical Assessment, Research, and Evaluation: Vol. 14, Article 16. DOI: https://doi.org/10.7275/vxrk-3190

Hansen, A. et al. (2011). Children's Errors in Mathematics: Understanding CommonMisconceptions in Primary Schools.

Herholdt \& Sapire, (2014). An error analysis in the early grades mathematics - a learning opportunity? South African Journal of Childhood

Education, 4(1), 19. https://doi.org/10.4102/sajce.v4i1.46

Jarrar, Elham Theeb Mahmoud (2014). The Impact of Remedial Classes on the Performance of the Fourth Grade Low Achievers on English in Public Schools in ramallah District. Published Thesis. An-Najah National University, Nablus, Palestine.

Pabilonia, K.R. (2014). Exponential and Logarithmic Functions Misconceptions anderrors: Basis for Instructional Guide development. Undergraduate Thesis. Lucban,Quezon: Southern Luzon State University

Pound Lee \& Trisha Lee (2011). Teaching Mathematics Creatively. London. New York:Routhledge Publishing.

Rushton, S. (2018). Teaching and learning mathematics through error analysis. Fields Math EducJ 3,4 (2018). https://doi.org/10.1186/s40928-018-0009-y

Salvaleon, A.P. (2011). Enhancement Learning Activities Based from the Multiple Intelligences of the Third Year High school Students in Chemistry. Undergraduate Thesis. Lucban,Quezon: Southern Luzon State University. 